\title{
Rostral cranial fossa as a site for cerebrospinal fluid drainage - volumetric studies in dog breeds of different size and morphotype
}

Wojciech Sokołowski ${ }^{1 *}$ D, Norbert Czubaj ${ }^{1}$, Michał Skibniewski ${ }^{1}$, Karolina Barszcz ${ }^{1}$, Marta Kupczyńska', Wojciech Kinda ${ }^{2}$ and Zdzisław Kiełbowicz ${ }^{2}$

\begin{abstract}
Background: Hydrocephalus is a multifactorial condition, whose aetiology is not fully understood. Congenital hydrocephalus frequently occurs in small and brachycephalic dog breeds. Although it is widely accepted that the cribriform plate located in the rostral cranial fossa (RCF) is a site of cerebrospinal fluid (CSF) drainage, the RCF has not been studied extensively. Literature reports indicate that a decreased caudal cranial fossa (CCF) volume in the course of the Chiari-like malformation may obstruct CSF circulation. We hypothesised that morphological diversity among different breeds in the volume of the RCF may affect CSF circulation. The aim of the study was to carry out a volumetric analysis of the RCF and the cranial cavity and to determine the ratio between them in dog breeds of different size and morphotype. We performed computed tomography (CT) morphometric analysis of the RCF compartment by obtaining volume measurements from the transverse and reformatted sagittal and dorsal planes.

Results: The rostral cranial fossa percentage - volume of the rostral cranial fossa/volume of cranial cavity $\times 100$ $($ volRCF/volCC $\times 100)$ was lower in small and brachycephalic dog breeds than in the other dogs.

Conclusions: A reduced RCF volume was detected in small and brachycephalic dog breeds, some of which are predisposed to congenital hydrocephalus. This may lead to overcrowding of brain parenchyma in the RCF and may impede CSF circulation. Our observations may be useful for future studies focusing on the causes and new therapies to treat conditions such as hydrocephalus and syringomyelia.
\end{abstract}

Keywords: Hydrocephalus, Lymphatic drainage, Cerebrospinal fluid, Dog, Rostral cranial fossa, Cribriform plate

\section{Background}

Hydrocephalus is a pathological condition caused by an imbalance between cerebrospinal fluid (CSF) production, flow and drainage. This results in an accumulation of CSF in the intracranial space, most commonly within the ventricular system [1]. Hydrocephalus is multifactorial condition. Small and brachycephalic breeds are predisposed to congenital hydrocephalus [2, 3]. The arachnoid villi, located in venous sinuses, and nasal lymphatics (NL) are the main site of CSF absorption. CSF

\footnotetext{
* Correspondence: wojciech.pawel.sokolowski@gmail.com

${ }^{1}$ Department of Morphological Sciences, Faculty of Veterinary Medicine,

Warsaw University of Life Sciences - SGGW, Nowoursynowska 159, 02-776

Warsaw, Poland

Full list of author information is available at the end of the article
}

enters to the nasal cavity and NL through the cribriform plate located in the rostral cranial fossa (RCF) $[1,4,5]$. Studies suggest that CSF is mainly absorbed into the NL if the intracranial pressure is normal. A disruption of this process may contribute to the development of central nervous system disorders, including hydrocephalus [6-8].

As opposed to the caudal cranial fossa (CCF), the RCF has not been studied volumetrically in dogs. The CCF structures have been studied extensively due to the occurrence of the Chiari-like malformation $(\mathrm{CM})$ in some breeds of small dogs [9-12]. CM has been frequently diagnosed in the Cavalier King Charles Spaniel and is associated with a disproportion between the

(C) The Author(s). 2018 Open Access This article is distributed under the terms of the Creative Commons Attribution 4.0 International License (http://creativecommons.org/licenses/by/4.0/), which permits unrestricted use, distribution, and 
volume of brain parenchyma and the CCF volume. The reduced CCF volume causes overcrowding of the cerebellum, pons and medulla and may cause syringomyelia (SM) due to disturbances in CSF circulation [13, 14].

We assumed that similar relationships may occur in the RCF. We hypothesised that in small and brachycephalic breeds predisposed to hydrocephalus the volume ratio of the RCF to the cranial cavity $(\mathrm{CC})$ is smaller than in the others. That may potentially cause "overcrowding" of brain structures and disrupt CSF flow through the cribriform plate to the NL. The aim of the study was to carry out a volumetric measurement of the RCF and $\mathrm{CC}$ and to assess the relationship between those parameters in dog breeds of various size and morphotype.

\section{Results}

\section{Morphotype}

Individuals were divided into four groups based on skull index. Dolichocephalic breed group (skull index $\leq 50.00$ ) consisted of 13 individuals ( 7 males and 6 females). Mesaticephalic 1 breed group (skull index 50.01-65.00) contained 33 individuals (16 males and 17 females). There were 12 animals in mesaticephalic 2 breed group (skull index 65.01-80.00) (9 males and 3 females). Brachycephalic breed group (skull index $\geq 80.01$ ) comprised 13 animals (3 males and 10 females). The different dog breeds in each group are presented in Table 1. Values of the rostral cranial fossa percentage were lower in group $B$ than in the remaining groups (Table 2). There were statistically significant differences in the analysed parameters between brachycephalic and dolichocephalic breed group $(p=0.0002)$ and brachycephalic and mesaticephalic 1 breed group $(p=0.0024)$. There were no statistically significant differences among the remaining groups.

\section{Breed size}

Individuals were divided into four groups based on the breed size. Small breed group contained 25 individuals (10 males and 15 females). Medium breed group comprised 17 individuals (9 males and 8 females). There were 20 animals (7 males and 13 females) in large breed group and nine in giant breed group ( 3 males and 6 females). The number of dogs of each breed is presented in Table 3. The rostral cranial fossa percentage reached lower values in small breed group than in the remaining groups (Table 2). There was a

Table 1 The number of dogs of different breeds in each group, division based on the skull index

\begin{tabular}{|c|c|c|c|c|c|c|c|}
\hline \multicolumn{2}{|l|}{ Dolichocephalic } & \multicolumn{2}{|l|}{ Mesaticephalic 1} & \multicolumn{2}{|l|}{ Mesaticephalic 2} & \multicolumn{2}{|c|}{ Brachycephalic } \\
\hline Breed & $\begin{array}{l}\text { Number of } \\
\text { dogs }\end{array}$ & Breed & $\begin{array}{l}\text { Number } \\
\text { of dogs }\end{array}$ & Breed & $\begin{array}{l}\text { Number } \\
\text { of dogs }\end{array}$ & Breed & $\begin{array}{l}\text { Number } \\
\text { of dogs }\end{array}$ \\
\hline $\begin{array}{l}\text { Black Russian } \\
\text { Terrier }\end{array}$ & 1 & $\begin{array}{l}\text { American Staffordshire } \\
\text { Terrier }\end{array}$ & 4 & $\begin{array}{l}\text { American Staffordshire } \\
\text { Terrier }\end{array}$ & 4 & $\begin{array}{l}\text { English } \\
\text { Bulldog }\end{array}$ & 2 \\
\hline $\begin{array}{l}\text { Dobermann } \\
\text { Pinscher }\end{array}$ & 1 & Australian Shepherd & 1 & Boxer & 3 & $\begin{array}{l}\text { French } \\
\text { Bulldog }\end{array}$ & 6 \\
\hline German Shepherd & 6 & $\begin{array}{l}\text { Bavarian Mountain } \\
\text { Hound }\end{array}$ & 1 & $\begin{array}{l}\text { Cavalier King Charles } \\
\text { Spaniel }\end{array}$ & 1 & Pekingese & 5 \\
\hline Great Dane & 1 & Bernese Mountain Dog & 1 & Italian Mastiff & 1 & & \\
\hline Newfoundland & 1 & Bull Terrier & 1 & Miniature Pinscher & 1 & & \\
\hline Scottish Terrier & 1 & Dachshund & 3 & Rottweiler & 1 & & \\
\hline $\begin{array}{l}\text { White Swiss } \\
\text { Shepherd }\end{array}$ & 1 & Dalmatian & 2 & Yorkshire Terrier & 1 & & \\
\hline \multirow[t]{11}{*}{ Wire Fox Terrier } & 1 & English Beagle & 1 & & & & \\
\hline & & German Shepherd & 3 & & & & \\
\hline & & $\begin{array}{l}\text { German Wirehaired } \\
\text { Pointer }\end{array}$ & 1 & & & & \\
\hline & & Italian Mastiff & 1 & & & & \\
\hline & & Labrador Retriever & 3 & & & & \\
\hline & & Miniature Pinscher & 2 & & & & \\
\hline & & Rottweiler & 3 & & & & \\
\hline & & Samoyed & 1 & & & & \\
\hline & & Schipperke & 1 & & & & \\
\hline & & Standard Schnauzer & 1 & & & & \\
\hline & & Yorkshire Terrier & 3 & & & & \\
\hline
\end{tabular}


Table 2 Statistical parameters for the rostral cranial fossa percentage for each group

\begin{tabular}{|c|c|c|c|c|c|c|}
\hline Group & Arithmetic Mean & Range & Median & Standard Deviation & Lower Quartile & Upper Quartile \\
\hline All Dogs & 9.803 & $6.293-15.194$ & 9.857 & 1.426 & 8.671 & 10.718 \\
\hline \multicolumn{7}{|c|}{ Division based on the skull index } \\
\hline Dolichocephalics & 10.989 & $9.922-12.257$ & 11.057 & 0.651 & 10.534 & 11.257 \\
\hline Mesaticephalics 1 & 9.970 & $7307-15,194$ & 10.214 & 1.502 & 8.864 & 10.718 \\
\hline Mesaticephalics 2 & 9.727 & $8.135-11,038$ & 9.585 & 0.851 & 9.230 & 10.421 \\
\hline Brachycephalics & 8.261 & $6.293-8985$ & 8.449 & 0.758 & 7.999 & 8.874 \\
\hline \multicolumn{7}{|c|}{ Division based on the breed size } \\
\hline Small Breeds & 8.511 & $6.293-11.114$ & 8.568 & 0.957 & 8.096 & 8.864 \\
\hline Medium Breeds & 10.091 & $8.877-12.007$ & 9.857 & 0.850 & 9.723 & 10.505 \\
\hline Large Breeds & 10.661 & $7.908-12.257$ & 10.728 & 0.924 & 10.305 & 11.062 \\
\hline Giant Breeds & 10.939 & $9.488-15.194$ & 10.499 & 1.699 & 10.214 & 11.153 \\
\hline
\end{tabular}

statistically significant difference between small and medium breed group $(p=0.0002)$, small and large breed group $(p=0.0002)$ and small and giant breed group $(p=0.0002)$. There were no statistically significant differences among the remaining groups. Rostral cranial fossa percentage values of different breeds in small breed group are presented in Table 4 .

\section{Discussion}

The cranial cavity can be divided into three regions called the RCF, middle cranial fossa and the CCF [15]. CSF, which is produced by the ventricle choroid plexus, flows from the ventricular system into the subarachnoid space via the lateral apertures of the fourth ventricle [15]. This occurs within the CCF, from where CSF is transported along the skull base through the middle cranial fossa to the area of olfactory bulbs located in the RCF [8]. Afterwards, the CSF passes through the cribriform plate foramina into the nasal cavity, where it reaches small lymphatic vessels. This connection has been confirmed in many species using Microfil, the silicon injection rubber compound, which was injected into the cerebellomedullary cistern. Microfil penetrated into the nasal cavity and its small lymphatic vessels [16-18]. Until recently, research on hydrocephalus has focused on the impaired outflow of CSF through the arachnoid villi, which are considered to be the major route for the absorption of CSF from the cranial cavity [19]. A study carried out on sheep suggested that in the case of low intracranial pressure, the majority of the CSF exits the cranial cavity through the cribriform plate and enters the lymphatic vessels of the nasal cavity. The arachnoid villi were described to act as a "safety valve", which is activated when the intracranial pressure increases [6].

Impaired CSF drainage may result in CNS disorders. A block to CSF flow in the region of the basal cisterns in

Table 3 The number of dogs of different breeds in each group, division based on the breed size

\begin{tabular}{|c|c|c|c|c|c|c|c|}
\hline \multicolumn{2}{|l|}{ Small Breeds } & \multicolumn{2}{|l|}{ Medium Breeds } & \multicolumn{2}{|l|}{ Large Breeds } & \multicolumn{2}{|l|}{ Giant Breeds } \\
\hline Breed & $\begin{array}{l}\text { Number } \\
\text { of dogs }\end{array}$ & Breed & $\begin{array}{l}\text { Number } \\
\text { of dogs }\end{array}$ & Breed & $\begin{array}{l}\text { Number } \\
\text { of dogs }\end{array}$ & Breed & $\begin{array}{l}\text { Number } \\
\text { of dogs }\end{array}$ \\
\hline $\begin{array}{l}\text { Cavalier King } \\
\text { Charles Spaniel }\end{array}$ & 1 & $\begin{array}{l}\text { American Staffordshire } \\
\text { Terrier }\end{array}$ & 8 & Black Russian Terrier & 1 & $\begin{array}{l}\text { Bernese Mountain } \\
\text { Dog }\end{array}$ & 1 \\
\hline Dachshund & 3 & Australian Shepherd & 1 & Boxer & 3 & Great Dane & 1 \\
\hline French Bulldog & 6 & $\begin{array}{l}\text { Bavarian Mountain } \\
\text { Hound }\end{array}$ & 1 & Dobermann Pinscher & 1 & Italian Mastiff & 2 \\
\hline Miniature Pinscher & 3 & Bull Terrier & 1 & German Shepherd & 9 & Newfoundland & 1 \\
\hline Pekingese & 5 & Dalmatian & 2 & German Wirehaired Pointer & 1 & Rottweiler & 4 \\
\hline Schipperke & 1 & English Bulldog & 2 & Labrador Retriever & 3 & & \\
\hline Scottish Terrier & 1 & English Beagle & 1 & Samoyed & 1 & & \\
\hline Wire Fox Terrier & 1 & Standard Schnauzer & 1 & $\begin{array}{l}\text { White Swiss } \\
\text { Shepherd }\end{array}$ & 1 & & \\
\hline Yorkshire Terrier & 4 & & & & & & \\
\hline
\end{tabular}


Table 4 The rostral cranial fossa percentage in the group of small dogs

\begin{tabular}{lll}
\hline Breed & Number of dogs & Value / Range \\
Pekingese & 5 & $6.293-8.671$ \\
French Bulldog & 6 & $8.096-8.985$ \\
Yorkshire Terrier & 4 & $7.307-8.670$ \\
Cavalier King Charles Spaniel & 1 & 8.803 \\
Miniature Pinscher & 3 & $8.110-9.112$ \\
Dachshund & 3 & $7.629-8.864$ \\
Schipperke & 1 & 9.455 \\
Scottish Terrier & 1 & 11.114 \\
Wire Fox Terrier & 1 & 10.483 \\
\hline
\end{tabular}

the middle cranial fossa resulted in hydrocephalus in the rat. Interestingly, the degree of cerebral ventricular enlargement was proportionate to the degree of impaired CSF flow through the cribriform plate [7]. In humans, $8 \%$ of surgeries within the skull base result in the formation of postoperative hydrocephalus. This may be a result of disrupted CSF flow caused by the formation of postoperative scars in that region [20]. Hence, hydrocephalus may also develop secondary to a disrupted CSF outflow through the cribriform plate [7].

Hydrocephalus can be congenital or acquired. Toy and brachycephalic breeds, such as the Pekingese, Yorkshire Terrier, Maltese, Miniature Poodle, Pomeranian, Chihuahua, Pug, Boston Terrier and English Bulldog are predisposed to congenital hydrocephalus $[2,3]$. This type of hydrocephalus is most frequently caused by a stenosis of the mesencephalic aqueduct although the exact obstruction site and the precise cause of the hydrocephalus often remains undiagnosed [2, 21]. Therefore, impaired flow of the CSF out of the cranial cavity may be a cause of congenital hydrocephalus. We found that the rostral cranial fossa percentage was smaller in small breed dogs compared to the other groups of dogs. Similar findings were obtained when comparing brachycephalic dogs with mesati- and dolichocephalic dogs. In the group of small breed dogs, the Yorkshire terrier, Pekingese, French bulldog, Miniature Poodle, Miniature Pinscher and Dachshund were found to have a decreased volume of the RCF. In the group of brachycephalic dogs, the size of the RCF was decreased in the French Bulldog, English Bulldog and Pekingese. Some of those breeds are predisposed to congenital hydrocephalus [3]. Ventricular enlargement without neurological symptoms has been described in the Yorkshire terrier and English bulldog. [22, 23]. Our data indicate that the RCF volume was decreased in some breeds predisposed to congenital hydrocephalus. However, the reduction of the RCF volume does not seem to be the sole cause of the disruption of intracranial CSF circulation. This is because the prevalence of hydrocephalus in breeds such as the Dachshund and Miniature Pinscher, which also have a reduced RCF volume, is much smaller. In theory, hydrocephalus in predisposed small and brachycephalic breeds may be caused by the overcrowding of brain structures in the RCF, impeding CSF outflow via the cribriform plate. However, further studies are needed to clarify this. The percentage volume of the brain parenchyma in the RCF in breeds with different morphotypes and size should be studied further. That would prove whether brain structures are crowded in the region of the cribriform plate.

The concept of the CSF flow being disrupted by the crowded brain structures is not novel. CCF pathologies may also cause disturbances in CSF flow. Some breeds of dogs suffer from CM [10,12, 24, 25], which is caused by occipital bone hypoplasia leading to a decreased CCF volume. This leads to "overcrowding" of brain structures within the CCF and causes an obstruction of CSF flow at the foramen magnum, which is considered one of the causes of SM. However, the pathophysiology of SM may be multifactorial [26, 27]. CM and SM most often occur in the Cavalier King Charles Spaniel [28]. They have also been described in the Griffon Bruxellois, Yorkshire Terrier, Maltese and the Poodle [12, 25, 29]. Other breeds of dogs that suffer from CM, such as the Chihuahua, Boston Terrier and Papillion, are at risk of developing SM [30]. The majority of those breeds are brachycephalic, toy or both. In some cases, SM is accompanied by ventricular enlargement $[25,29]$. This is in accordance with our findings, where we observed a decreased volume of the RCF, a site of CSF outflow, in brachycephalic and small breed dogs. In breeds with CM, the volume of the CCF and RCF may be decreased. That may significantly disrupt CSF circulation. The association between a decreased RCF volume and SM warrants further study.

\section{Conclusions}

The determination of volume ratios between different compartments of the cranial cavity is essential to understand certain CNS disorders associated with disrupted CSF circulation. Our results indicate that the ratio of RCF volume to CC volume is lower in small and brachycephalic breeds of dogs. A small rostral cranial fossa percentage is found in dogs predisposed to congenital hydrocephalus. We are aware that our findings do not prove impaired CSF outflow through the cribriform plate. However, they could form the basis for future research on this area of the cranial cavity. The ratios of the brain parenchyma within the RCF to the volume of the RCF should be calculated. The flow of CSF through the cribriform plate to the 


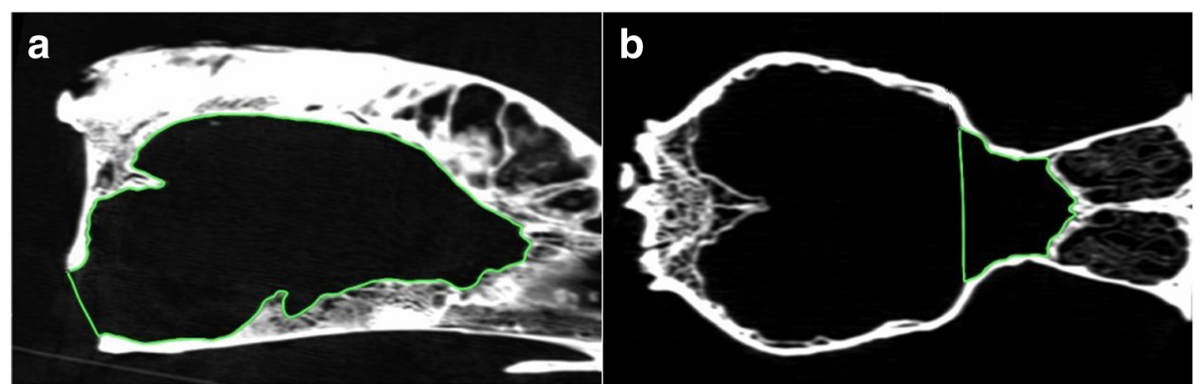

Fig. 1 Regions of interest used to calculate volCC (a) and volRCF (b)

NL should be thoroughly studied in dogs with hydrocephalus.

\section{Methods}

\section{Material}

Seventy-one skulls obtained from adult dogs of both genders (35 males and 36 females) from 2 to 16 years old were analyzed. Mixed-breed dogs and mongrel dogs were not included in the study. The skulls were divided based on the breed size into small, medium, large and giant breed group. Based on the skull index individuals were divided into the dolichocephalic, mesaticephalic 1 , mesaticephalic 2 and brachycephalic breed group [15].

The skulls were obtained from animals euthanised by veterinary doctors at the Small Animal Clinic of the Department of Clinical Sciences, Faculty of Veterinary Medicine, of the Warsaw University of Life Sciences.
The animals were not euthanized for the purpose of this study. The owners consented to the euthanasia and to the use of the animal tissue for scientific purposes. None of the animals had any neurological symptoms prior to euthanasia. Examined animals were adults, with closed skull sutures and without dome-shaped skull. According to the Polish law, the post mortem use of tissue does not require the approval from the Ethics Committee (Parliament of the Republic of Poland, 2015). The corpses were subjected to a process of maceration. Soft tissue were removed from cranial cavity prior to CT examination.

\section{CT analysis}

Computed tomography images of the skulls placed in ventral recumbency were acquired with a helical CT scanner (Siemens SOMATOM Emotion 16 CT Scanner) and a slice thickness of $0.75 \mathrm{~mm}$ to provide detailed

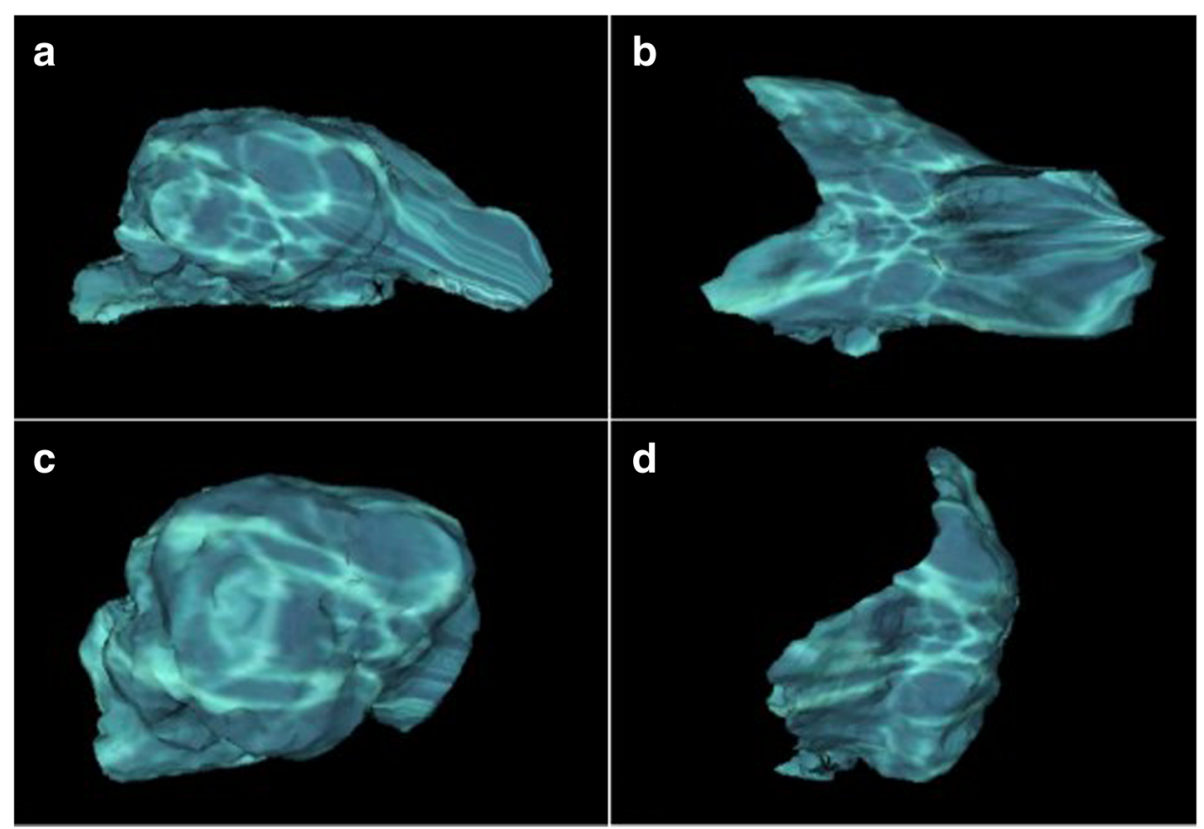

Fig. 2 The three-dimensional model of cranial cavity (a) and rostral cranial fossa (b) in dolichocephalic dog; cranial cavity (c) and rostral cranial fossa (d) in brachycephalic dog 
image of the cranial cavity. Images were reconstructed with bone filter and displayed using a bone window (window width $2000 \mathrm{HU}$ and window level $350 \mathrm{HU}$ ). In some cases the window was adjusted manually to better outline specific bony structures. CT data were transferred as a DICOM file to an image analysis workstation with Osirix ${ }^{\bullet}$ software in order to perform the image analysis. The originally obtained transverse slices were reformatted into the sagittal and dorsal planes. The volCC (volume of cranial cavity) and volRCF (volume of the rostral cranial fossa) were calculated. The volCC was obtained using the slice by slice method. The region of interest (ROI) was selected on each slice in the sagittal plane (Fig. 1). Next, a three-dimensional model presenting the volume was created using the ROI Volume function (Fig. 2). The dorsal and ventral margin of the foramen magnum formed the caudal border of the cranial cavity. The volRCF was obtained through the same method (Figs. 1 and 2). The ROI was selected using the dorsal plane. The bone protrusion corresponding to the presylvian fissure formed the caudal margin of this ROI. Only those skulls, where this bony protrusion was easily identifiable, were included in the study. At the skull base, the caudal edge of the prechiasmatic sulcus formed the caudal margin of the RCF. Those values were used to calculate the rostral cranial fossa percentage $=$ volRCF $/$ volCC $\times 100$.

The linear AP, which is the distance between the Akrokranion - Prosthion, was measured in the median plane. The Akrokranion is the most caudal point of the calvaria and the Prosthion is the most rostral point of the interincisive suture. The linear $\mathrm{ZyZy}$, which is the distance between the most protruding points of the zygomatic arch, was measured in the dorsal plane. Those measurements were used to calculate the skull index $=\mathrm{ZyZy} / \mathrm{AP} \times 100$ [15].

\section{Statistical analysis}

The Statistica 10.0 (StatSoft, Inc.) software was used to assess the results. The distribution of the variables in the examined population was evaluated using the W Shapiro-Wilk test. The obtained data had a normal distribution, and they were analysed using the one-way analysis of variance. The effect of the breed size and the morphotype of the animals on the rostral cranial fossa percentage were assessed separately. Statistical significance between the groups was calculated using Tukey's honestly significant difference (HSD) test.

\section{Additional file}

Additional file 1: Individuals value of AP, ZyZy, volRCF, volCC and volRCF/volCC ratio (RCF/CC). (XLS $20 \mathrm{~kb}$ )

\section{Abbreviations}

AP: Distance between the Akrokranion - Prosthion; CC: Cranial cavity; CCF: Caudal cranial fossa; CM: Chiari-like malformation; CSF: Cerebrospinal fluid; NL: Nasal lymphatics; RCF: Rostral cranial fossa; ROI: Region of interest; volCC: Volume of cranial cavity; volRCF: Volume of the rostral cranial fossa; ZyZy: Distance between the most protruding points of the zygomatic arch

Availability of data and materials

The datasets supporting the conclusions of this article are included within the article (and its Additional file 1).

\section{Author's contributions}

WS designed the study, performed the volumetric analysis, drafted the manuscript and recruited material. NC assisted with volumetric analysis, recruited material and helped to draft the manuscript. MS performed the statistical analysis. KB and MK recruited material and helped to draft the manuscript. WK and ZK performed the CT examination of the skulls. All authors read and approved the final manuscript.

\section{Ethical approval and Consent}

Not applicable.

\section{Competing interests}

The authors declare that they have no competing interests.

\section{Publisher's Note}

Springer Nature remains neutral with regard to jurisdictional claims in published maps and institutional affiliations.

\section{Author details}

${ }^{1}$ Department of Morphological Sciences, Faculty of Veterinary Medicine, Warsaw University of Life Sciences - SGGW, Nowoursynowska 159, 02-776 Warsaw, Poland. ${ }^{2}$ Department of Surgery, Faculty of Veterinary Medicine, Wroclaw University of Environmental and Life Sciences, Pl. Grunwaldzki 51, 50-366, Wroclaw, Poland.

Received: 1 June 2016 Accepted: 2 May 2018

Published online: 18 May 2018

\section{References}

1. Zakrzewski K. Wodogłowie i inne zaburzenia krążenia płynu mózgowordzeniowego u dzieci. $1^{\text {st }}$ ed. Wydawnictwo Czelej; 2007.

2. De Lahunta A, Glass EN, Kent M. Veterinary neuroanatomy and clinical neurology. 4th ed. St.Louis: Elsevier Health Sciences; 2014.

3. Platt SR, Olby NJ. BSAVA manual of canine and feline neurology. 4th ed. Gloucester: British Small Animal Veterinary Association; 2014.

4. Boulton M, Flessner M, Armstrong D, Mohamed R, Hay J, Johnston M. Contribution of extracranial lymphatics and arachnoid villi to the clearance of a CSF tracer in the rat. Am J Phys. 1999;276:818-23.

5. Boulton $M$, Flessner $M$, Armstrong $D$, Hay J, Johnston M. Determination of volumetric cerebrospinal fluid absorption into extracranial lymphatics in sheep. Am J Phys. 1998;274:88-96.

6. Mollanji R, Bozanovic-Sosic R, Silver I, Li B, Kim C, Midha R, Johnston M. Intracranial pressure accommodation is impaired by blocking pathways leading to extracranial lymphatics. Am J Physiol Regul Integr Comp Physiol. 2001;280:1573-81

7. Nagra G, Li J, McAllister JP, Miller J, Wagshul M, Johnston M. Impaired lymphatic cerebrospinal fluid absorption in a rat model of kaolin-induced communicating hydrocephalus. Am J Physiol Regul Integr Comp Physiol. 2008;294:1752-9.

8. Murtha LA, Yang Q, Parsons MW, Levi CR, Beard DJ, Spratt NJ, McLeod DD Cerebrospinal fluid is drained primarily via the spinal canal and olfactory route in young and aged spontaneously hypertensive rats. Fluids Barriers CNS. 2014; https://doi.org/10.1186/2045-8118-11-12.

9. Cross HR, Cappello R, Rusbridge C. Comparison of cerebral cranium volumes between cavalier king Charles spaniels with Chiari-like malformation, small breed dogs and Labradors. J Small Anim Pract. 2009;50:399-405.

10. Rusbridge C, Knowler SP, Pieterse L, McFadyen AK. Chiari-like malformation in the griffon Bruxellois. J Small Anim Pract. 2009;50:386-93.

11. Schmidt MJ, Amor KH, Failing K, Klingler M, Kramer M, Ondreka N. Comparison of the endocranial- and brain volumes in brachycephalic dogs, mesaticephalic 
dogs and cavalier king Charles spaniels in relation to their body weight. Acta Vet Scand. 2014; https:/doi.org/10.1186/1751-0147-56-30

12. Cagle L. Concurrent occipital hypoplasia, occipital dysplasia syringohydromyelia, and hydrocephalus in a Yorkshire terrier. Can Vet J. 2010;51:904-8.

13. Rusbridge C, MacSweeny JE, Davies JV, Chandler K, Fitzmaurice SN, Dennis R, Capello R, Wheeler SJ. Syringohydromyelia in cavalier king Charles spaniels. J Am Anim Hosp Assoc. 2000;36:34-41.

14. Czubaj N, Skibniewski M, Barszcz K, Sokołowski W. Clinical anatomy of syringomyelia and chiari malformation in dogs. Med Weter. 2015;71:146-51.

15. Evans HE, De Lahunta A. Miller's anatomy of the dog. 4th ed: Elsevier Health Sciences; 2013.

16. Johnston M, Zakharov A, Papaiconomou C, Salmasi G, Armstrong D. Evidence of connections between cerebrospinal fluid and nasal lymphatic vessels in humans, non-human primates and other mammalian species. Cerebrospinal Fluid Res. 2004; https://doi.org/10.1186/1743-8454-1-2.

17. Zakharov A, Papaiconomou C, Koh L, Djenic J, Bozanovic-Sosic R, Johnston M. Integrating the roles of extracranial lymphatics and intracranial veins in cerebrospinal fluid absorption in sheep. Microvasc Res. 2004;67:96-104.

18. Zakharov A, Papaiconomou C, Djenic J, Midha R, Johnston M. Lymphatic cerebrospinal fluid absorption pathways in neonatal sheep revealed by subarachnoid injection of microfil. Neuropathol Appl Neurobiol. 2003;29:563-73.

19. Massicotte EM, Del Bigio MR. Human arachnoid villi response to subarachnoid hemorrhage: possible relationship to chronic hydrocephalus. J Neurosurg. 1999;91:80-4.

20. Duong DH, O'Malley S, Sekhar LN, Wright DG. Postoperative hydrocephalus in cranial base surgery. Skull Base Surg. 2000;10:197-200.

21. Thomas WB. Hydrocephalus in dogs and cats. Vet Clin North Am Small Anim Pract. 2010;40:143-59.

22. Vite $\mathrm{CH}$, Insko EK, Schotland HM, Panckeri K, Hendricks JC. Quantification of cerebral ventricular volume in English bulldogs. Vet Radiol Ultrasound. 1997; 38:437-43.

23. Esteve-Ratsch B, KneissI S, Gabler C. Comparative evaluation of the ventricles in the Yorkshire terrier and the German shepherd dog using low-field MRI. Vet Radiol Ultrasound. 2001;42:410-3.

24. Rusbridge C, Knowler SP. Coexistence of occipital dysplasia and occipital hypoplasia/syringomyelia in the cavalier king Charles spaniel. J Small Anim Pract. 2006:47:603-6.

25. Park C, Kang BT, Yoo JH, Park HM. Syringomyelia in three small breed dogs secondary to Chiari-like malformation: clinical and diagnostic findings. J Vet Sci. 2009:10:365-7.

26. Rusbridge C, Greitz D, Iskandar BJ. Syringomyelia: current concepts in pathogenesis, diagnosis, and treatment. J Vet Intern Med. 2006;20:469-79.

27. Driver CJ, Volk HA, Rusbridge C, Van Ham LM. An update on the pathogenesis of syringomyelia secondary to Chiari-like malformations in dogs. Vet J. 2013;198:551-9.

28. Couturier J, Rault D, Cauzinille L. Chiari-like malformation and syringomyelia in normal cavalier king Charles spaniels: a multiple diagnostic imaging approach. J Small Anim Pract. 2008:49:438-43.

29. Freeman AC, Platt SR, Kent M, Huguet E, Rusbridge C, Holmes S. Chiari-like malformation and syringomyelia in American Brussels griffon dogs. J Vet Intern Med. 2014:28:1551-9.

30. Marino DJ, Loughin CA, Dewey CW, Marino LJ, Sackman JJ, Lesser ML, Akerman MB. Morphometric features of the craniocervical junction region in dogs with suspected Chiari-like malformation determined by combined use of magnetic resonance imaging and computed tomography. Am J Vet Res. 2012;73:105-11.

\section{Ready to submit your research? Choose BMC and benefit from:}

- fast, convenient online submission

- thorough peer review by experienced researchers in your field

- rapid publication on acceptance

- support for research data, including large and complex data types

- gold Open Access which fosters wider collaboration and increased citations

- maximum visibility for your research: over $100 \mathrm{M}$ website views per year

At BMC, research is always in progress.

Learn more biomedcentral.com/submissions 